\title{
Suppression of dynamin GTPase decreases a-synuclein uptake by neuronal and oligodendroglial cells: a potent therapeutic target for synucleinopathy
}

\author{
Masatoshi Konno ${ }^{1}$, Takafumi Hasegawa ${ }^{1 *}$, Toru Baba ${ }^{1}$, Emiko Miura ${ }^{1}$, Naoto Sugeno ${ }^{1}$, Akio Kikuchi ${ }^{1}$, \\ Fabienne C Fiesel ${ }^{2}$, Tsutomu Sasaki ${ }^{3}$, Masashi Aoki ${ }^{1}$, Yasuto Itoyama ${ }^{4}$ and Atsushi Takeda ${ }^{1}$
}

\begin{abstract}
Background: The intracellular deposition of misfolded proteins is a common neuropathological hallmark of most neurodegenerative disorders. Increasing evidence suggests that these pathogenic proteins may spread to neighboring cells and induce the propagation of neurodegeneration.

Results: In this study, we have demonstrated that a-synuclein (aSYN), a major constituent of intracellular inclusions in synucleinopathies, was taken up by neuronal and oligodendroglial cells in both a time- and concentration-dependent manner. Once incorporated, the extracellular aSYN was immediately assembled into high-molecular-weight oligomers and subsequently formed cytoplasmic inclusion bodies. Furthermore, aSYN uptake by neurons and cells of the oligodendroglial lineage was markedly decreased by the genetic suppression and pharmacological inhibition of the dynamin GTPases, suggesting the involvement of the endocytic pathway in this process.

Conclusions: Our findings shed light on the mode of aSYN uptake by neuronal and oligodendroglial cells and identify therapeutic strategies aimed at reducing the propagation of protein misfolding.
\end{abstract}

Keywords: a-synuclein, Neuron, Oligodendroglia, Transmission, Inclusions, Endocytosis, Dynamin, Sertraline, Parkinson's disease, Multiple system atrophy

\section{Background}

Lewy bodies (LBs), which are the cardinal histological hallmark of Parkinson's disease (PD), contain abnormal filamentous $\alpha$-synuclein $(\alpha \mathrm{SYN})$ aggregates. In addition, a variety of other neurodegenerative diseases are associated with $\alpha \mathrm{SYN}$-positive lesions [1,2]. The presence of $\alpha \mathrm{SYN}$ in LBs, Lewy neurites or glial cytoplasmic inclusions (GCIs) in PD and related disorders provides a conceptual link that has led to the use of the term 'synucleinopathy' to encompass these diseases [3-5]. Emerging evidence from genetic and biochemical studies demonstrates that abnormal $\alpha \mathrm{SYN}$ aggregates directly contribute to neurodegeneration in PD and other synucleinopathies [6-10]. Because

\footnotetext{
* Correspondence: thasegawa@med.tohoku.ac.jp

'Division of Neurology, Department of Neuroscience and Sensory Organs, Tohoku University Graduate School of Medicine, Sendai, Miyagi 980-8574, Japan

Full list of author information is available at the end of the article
}

$\alpha S Y N$ is enriched in the presynaptic nerve terminals and is mainly detected in the cytosolic and synaptosomal fractions, it has long been believed that $\alpha \mathrm{SYN}$ exerts its physiological as well as pathogenic effects intracellularly $[11,12]$. However, accumulating evidence suggests that both monomeric and oligomeric $\alpha \mathrm{SYN}$ can be secreted into the extracellular milieu, thereby affecting the normal physiological state of neighboring cells [13-17]. For example, in vitro-generated soluble $\alpha S Y N$ oligomers can induce the transmembrane seeding of $\alpha \mathrm{SYN}$ aggregation and can eventually lead to cell death $[18,19]$. Moreover, exogenous $\alpha \mathrm{SYN}$ fibrils have been shown to induce perikaryal LB pathology, which can lead to synaptic dysfunction and neuronal cell death [20]. The existence of the transcellular spread of $\alpha \mathrm{SYN}$ has also been verified by coculture experiments and in vivo animal models, which showed that $\alpha \mathrm{SYN}$ aggregates released from neuronal cells 
can be transferred to neighboring cells and form inclusion bodies [21-23]. Finally, the existence of an in vivo intercellular propagation of $\alpha S Y N$ aggregates was supported by recent observations of LB-like inclusions in the grafted neurons of PD patients who had received transplants of fetal mesencephalic neurons more than a decade previously [24-26]. In addition to PD, the intercellular transmission of $\alpha S Y N$ pathology can be assumed to be present in multiple system atrophy (MSA), in which widespread $\alpha S Y N-p o s i t i v e$ GCIs are found in oligodendroglia, a type of brain cell that does not normally express $\alpha S Y N$ [27-29]. Phenomenologically, the propagation theory is also attractive as an explanation for the hierarchical distribution of Lewy pathology in PD, a theory proposed by Braak and colleagues [30]. To understand how $\alpha \mathrm{SYN}$ travels from cell to cell, the underlying mechanisms responsible for $\alpha \mathrm{SYN}$ uptake and secretion must be elucidated. In this study, we provide evidence to support the functional role of dynamin-mediated endocytosis in the process of $\alpha \mathrm{SYN}$ uptake by neurons and oligodendroglial cells. Furthermore, we propose therapeutic strategies aimed at reducing the propagation of protein misfolding in synucleinopathies.

\section{Results}

\section{The characterization of recombinant a-synuclein}

Ectopically expressed proteins were collected from crude bacterial lysates and analyzed by sodium dodecyl sulfatepolyacrylamide gel electrophoresis (SDS-PAGE) followed by Coomassie brilliant blue (CBB) staining and immunoblotting with an anti- $\alpha \mathrm{SYN}$ antibody (Ab). Upon isopropyl $\beta$-D-1-thiogalactopyranoside (IPTG) induction, the BL21(DE3)pLysS E. coli was transformed with pGEX6P$1 / \alpha S Y N$, which produced a GST- $\alpha S Y N$ fusion protein that migrated at $44 \mathrm{kDa}$ under denaturing conditions (Figure 1A, asterisk). After enzymatic removal of the GST-tag, monomeric $\alpha S Y N$ was detected at a molecular mass of approximately $18 \mathrm{kDa}$, which was larger than the predicted value of $14 \mathrm{kDa}$ (Figure $1 \mathrm{~A}$ (a), arrowhead). Immunoblot analysis, using the anti-GST antibody, did not detect any remaining GST- $\alpha$ SYN after the removal of the GST moiety. The slow gel mobility may be attributed to the weak binding of SDS due to the highly acidic C-terminal sequence of $\alpha S Y N$ [31]. However, under native conditions, the majority of the recombinant $\alpha S Y N$ migrated to a position corresponding to approximately $54 \mathrm{kDa}$, which was assumed to be composed mainly of trimers as well as a few monomers and oligomers/multimers (Figure 1A (b)). It is important to note that the recombinant $\alpha \mathrm{SYN}$ did not self-assemble into SDS-resistant, soluble oligomers after 24 hours at $37^{\circ} \mathrm{C}$ in the cell-free culture medium (Figure 1A (c)). There was no visible band in the PBS washing buffer that flowed through the column, as revealed by $\mathrm{CBB}$ staining and $\alpha S Y N$ immunoblotting (data not shown).
Extracellular a-synuclein was incorporated and assembled into oligomers in neuronal and oligodendroglial cells

To elucidate how $\alpha \mathrm{SYN}$ is internalized into cells, human SH-SY5Y neuronal and KG1C oligodendroglial cells $[32,33]$ were exposed to $5 \mu \mathrm{M} \alpha \mathrm{SYN}$ for the indicated amount of time, and then subjected to fractionation and immunoblot analysis (Figure 1B (a) and (b), respectively). The KG1C cells used in the present study were confirmed to express oligodendroglial markers, including CNPase and myelin basic protein [34]. Interestingly, only one minute after the addition of $\alpha \mathrm{SYN}$, monomeric $\alpha \mathrm{SYN}$ (X1) had been incorporated and then continued to increase mainly in hydrophilic fraction. In parallel, the SDS-stable dimeric/trimeric $\alpha$ SYN (X2-X3), as well as the multimers and truncated fragments (arrow), also gradually appeared in hydrophilic fraction. Similarly, a dose-dependent increase in the intracellular monomeric and oligomeric forms of $\alpha \mathrm{SYN}$ was observed in the SH-SY5Y cells that were exposed to different concentrations of recombinant $\alpha S Y N(0-10 \mu \mathrm{M})$ for 24 hours (Figure 1B (c)). To clearly identify the high-molecular-weight (HMW) $\alpha \mathrm{SYN}$ species, the same blot was stripped and reprobed with the rabbit polyclonal $\alpha$ SYN Ab (\#2628, Cell Signaling Technology) to eliminate the non-specific band detected by the antisynuclein-1 Ab (Figure 1B (d)). In addition, the amount of monomeric $\alpha S Y N$ in the hydrophilic fractions of exposed cells was quantitatively measured by densitometric analysis (Additional file 1: Figure S1A (a)-(c). Similarly to the untagged $\alpha S Y N$, the GST- $\alpha S Y N$ added to the culture medium was time-dependently incorporated into SHSY5Y cells and formed GST-immunopositive oligomers and an HMW smear mainly in the hydrophilic fraction, demonstrating that extracellular $\alpha \mathrm{SYN}$ was internalized and oligomerized in the exposed cells (Additional file 1: Figure S1B). In mammals, the SYN family consists of three members $(\alpha-, \beta-, \gamma-)$, and all SYN genes are well conserved across species [35]. Importantly, we found that $\alpha \mathrm{SYN}$ was exclusively internalized into cells compared to $\beta$-synuclein $(\beta S Y N)$ and $\gamma$-synuclein $(\gamma S Y N)$. In addition, the familial PD-linked A30P and A53T mutations of $\alpha$ SYN enhanced the buildup of the SDS-stable HMW species when compared to the wt- $\alpha$ SYN (Additional file 2: Figure S2). It is important to note that $\alpha \mathrm{SYN}(10 \mu \mathrm{M})$ exposure for up to 10 days did not result in any changes in the cellular morphology or growth retardation (data not shown).

\section{The formation of cytoplasmic inclusions in neuronal and oligodendroglial cells exposed to a-synuclein}

Immunocytochemistry showed that large perinuclear inclusions, as well as small aggregates, were observed in the SH-SY5Y and KG1C cells exposed to $5 \mu \mathrm{M}$ recombinant $\alpha S Y N$ for up to 24 hours. In both cell lines after treatment, the $\alpha \mathrm{SYN}$-positive large inclusions and small aggregates were positive for ubiquitin and thioflavin $\mathrm{S}$ 


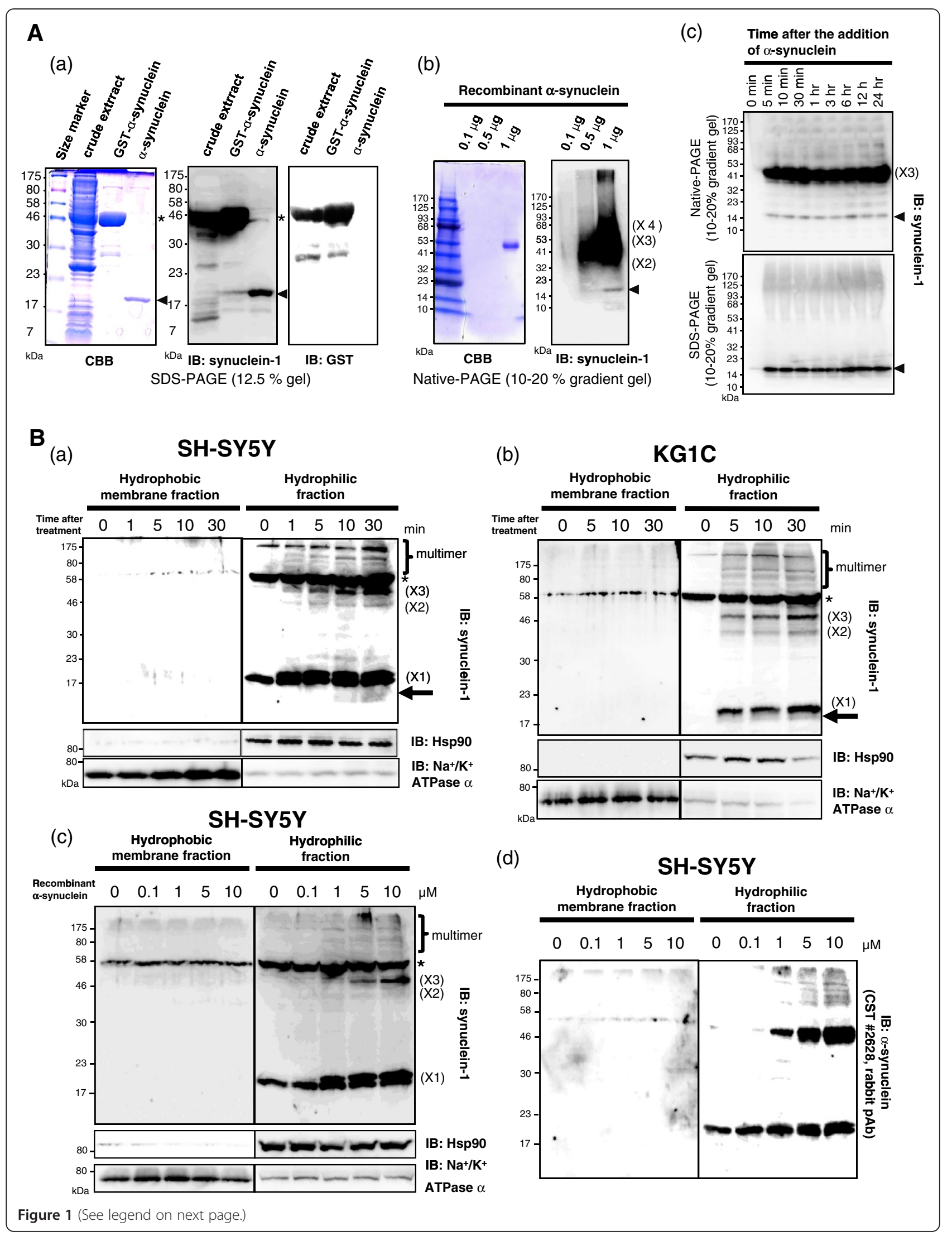


(See figure on previous page.)

Figure 1 Extracellular a-synuclein is internalized and assembled into SDS-stable oligomers in neuronal and oligodendroglial cells. A, The characterization of recombinant aSYN. (a) The expressed GST-aSYN and tag-free aSYN were analyzed by CBB staining and western blotting with an anti-aSYN Ab (1 $\mu \mathrm{g}$ per lane). Upon IPTG induction, the transformed E. coli produced a GST-aSYN fusion protein that migrated at $44 \mathrm{kDa}$ under denaturing conditions (asterisk). Following the removal of the GST-tag, monomeric aSYN was detected, which corresponded to a molecular mass of $18 \mathrm{kDa}$ (arrowhead). An immunoblot using an anti-GST antibody did not detect any GST-aSYN after the removal of the GST moiety. (b) In the native condition, the absolute majority of recombinant aSYN migrated to approximately $54 \mathrm{kDa}$, corresponding to trimeric (X3) aSYN as well as some monomers (arrowhead) and oligomers (X2 and X4)/multimers. (c) Recombinant aSYN in cell-free culture medium did not self-assemble into SDS-stable oligomers after 24 hours at $37^{\circ}$ C. B, Extracellular aSYN was incorporated and assembled into oligomers in neuronal and oligodendroglial cells. SH-SY5Y (a) and KG1C (b) cells were exposed to $5 \mu \mathrm{M}$ aSYN for the indicated amount of time, and the cells were then subjected to fractionation and aSYN immunoblot analysis ( $50 \mu \mathrm{g}$ lysate per lane). One minute after the addition of aSYN, monomeric aSYN (X1) was incorporated, and the amount of aSYN increased thereafter mainly in the hydrophilic fraction. In parallel, the SDS-resistant dimeric/trimeric aSYN (X2-X3), as well as the multimers and truncated fragments (arrow), gradually appeared in the hydrophilic fractions. Hsp90 and $\mathrm{Na}^{+} / \mathrm{K}^{+}$ATPase a were used as markers for the cytosol and the plasma membrane, respectively. (c) A dose-dependent increase in intracellular monomeric (X1) and oligomeric (X2-X3) aSYN was observed mainly in the hydrophilic fractions prepared from the cells exposed to varying concentrations of recombinant aSYN (0-10 $\mu M)$ for 24 hours. An asterisk indicates the non-specific band. Representative blots from three independent experiments are presented.

staining, but only the large inclusions were coimmunostained for serine 129-phosphorylated $\alpha S Y N$ in both cells. Neither $\alpha \mathrm{SYN}$-positive inclusions nor small aggregates were detected in control cells treated with the column flow-through (Figure 2A (a) and (b)). The spatial co-localization of ubiquitin and the $\alpha S Y N-$ positive inclusions was confirmed by orthogonal reconstructions from confocal z-stacks in the xz- and yzplanes. Furthermore, the double-immunolabeling studies, depicted in Figure 2B (a) and (b), demonstrated that the large juxtanuclear large inclusions were not only colocalized with $\gamma$-tubulin and peripherin but were also enveloped within a vimentin cage, suggesting that the molecular machinery controlling aggresomal formation may contribute to their biogenesis [2]. Of note, the $\alpha S Y N$ positive inclusion bodies in the KG1C cells were colocalized with tubulin-polymerization-promoting protein/ p25 $\alpha$ (TPPP/p25 $\alpha$ ), a known marker of GCI in the affected brain lesions of MSA patients [34,36,37]. The formation of $\alpha S Y N$-positive cytoplasmic inclusions was also confirmed in primary rat cortical neurons treated under the same condition, suggesting that these results were not a cell line-specific phenomenon (Figure $2 \mathrm{C}$ ). The percentage of perinuclear inclusion-bearing SH-SY5Y and KG1C cells increased in a time-dependent manner, reaching 35\% and $24 \%$, respectively, at 24 hours (Figure 2D).

\section{Lysosomal inhibition enhanced a-synuclein oligomer formation and impaired autophagic flux}

The $\alpha S Y N$-positive aggregates in the cells exposed to recombinant $\alpha S Y N$ were partially co-localized with the markers for early endosomes (Rab5A) and lysosomes (Lamp-1) (Figure 3A). To confirm the role of the intact lysosomal system in the degradation of incorporated $\alpha \mathrm{SYN}, \mathrm{SH}-\mathrm{SY} 5 \mathrm{Y}$ cells were treated with the vacuolar $\mathrm{H}^{+}$ ATPase inhibitor bafilomycin A1 (0-5 nM) together with $5 \mu \mathrm{M} \alpha \mathrm{SYN}$ for 24 hours. Following the fractionation process, all samples were analyzed by western blot analysis (Figure 3B). As shown by the immunoblotting, bafilomycin treatment increased the intracellular accumulation of HMW $\alpha S Y N$ oligomers in the hydrophilic fraction of $\alpha \mathrm{SYN}$-exposed cells in a dose-dependent manner. In contrast, bafilomycin treatment did not affect the level of endogenous $\alpha S Y N$ in the control cells lacking $\alpha \mathrm{SYN}$ exposure. In the $\alpha \mathrm{SYN}$-treated SH-SY5Y cells, co-treatment with bafilomycin augmented the induction of LC3-II protein, which is indicative of an increase in macroautophagy and autophagosome formation. Under this condition, we could not detect caspase-3 cleavage, a hallmark of apoptosis (Figure 3C). Hence, lysosomal inhibition impairs the autophagic flux in $\alpha S Y N$-treated neuronal and oligodendroglial cells.

\section{The inhibition of dynamin GTPases decreased a-synuclein internalization by neuronal and oligodendroglial cells}

The internalization of $\alpha \mathrm{SYN}$ oligomers is thought to be mediated by endocytosis because K44A dynamin 1, a dominant-negative mutant that blocks endocytic vesicle formation, was previously shown to reduce the number of incorporated $\alpha \mathrm{SYN}$ aggregates in COS-7 cells and primary astrocytes $[21,38,39]$. The enhanced endocytosis of preformed fibrils of $\alpha \mathrm{SYN}$ in response to the addition of wheat germ agglutinin (WGA) was shown to increase the extent of pathology in cultured neuronal cells [20]. Lee and his colleagues have shown that monomeric $\alpha S Y N$ can be internalized into cells without endocytosis, whereas aggregated forms enter cells via endocytosis [19,39]. Complementarily, the inhibition of endocytosis decreased the cellular uptake of $\alpha \mathrm{SYN}$ in vitro and in vivo [22]. The involvement of the endocytic process during $\alpha \mathrm{SYN}$ internalization is further supported by a previous proteomic analysis showing that microglial activation, secondary to the internalization of aggregated $\alpha S Y N$, requires clathrin, which plays major roles in endocytosis and vesicular trafficking [40]. Of the three dynamin isoforms identified thus far, dynamin 1 and dynamin 2 are mainly 


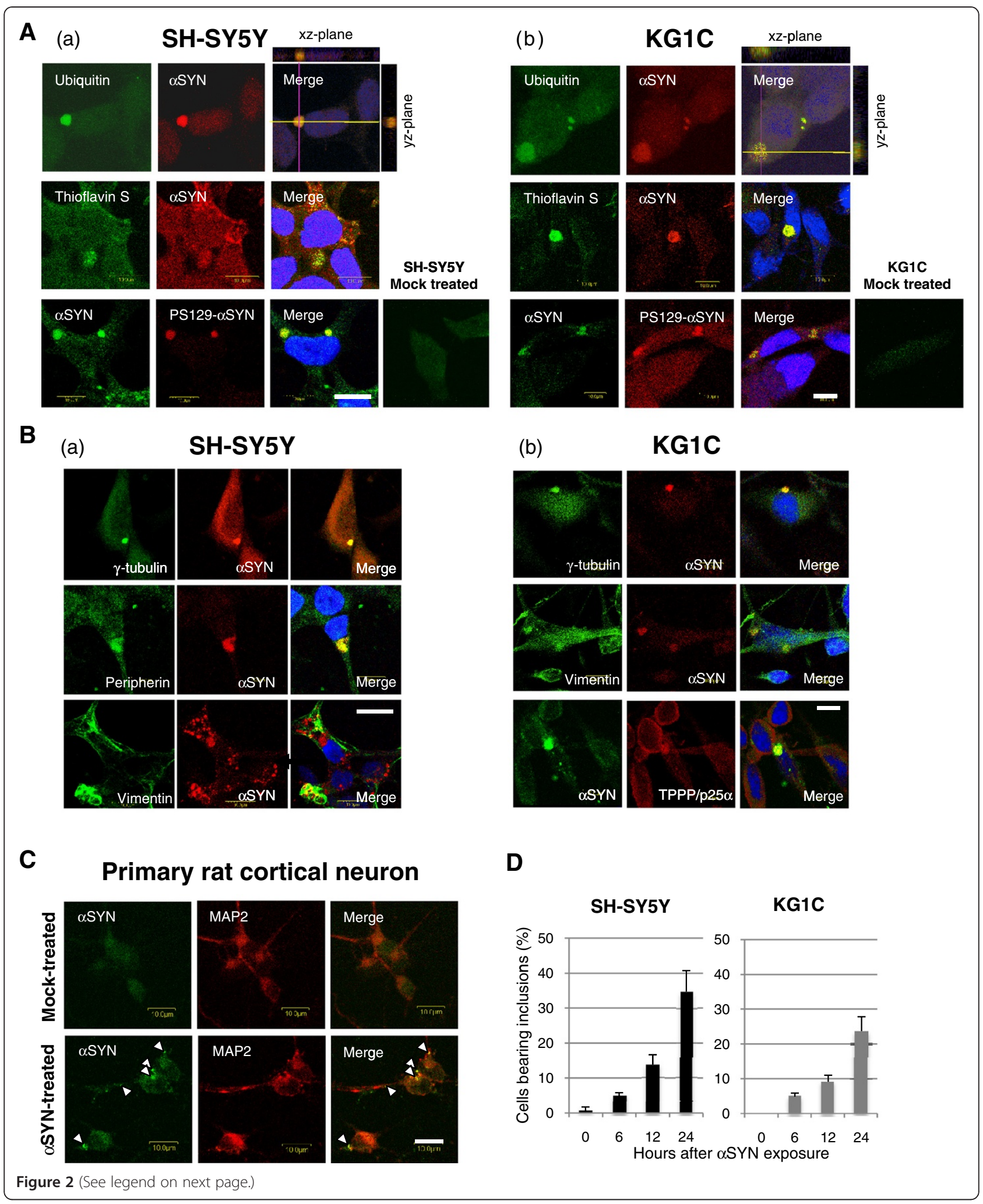


(See figure on previous page.)

Figure $\mathbf{2}$ The formation of cytoplasmic inclusions in neuronal and oligodendroglial cells exposed to a-synuclein. A, Large perikaryal inclusions as well as small aggregates were observed in the SH-SY5Y (a) and KG1C (b) cells exposed to $5 \mu$ M recombinant aSYN for 24 hours. The aSYN-positive inclusions and small aggregates were positive for ubiquitin and thioflavin $\mathbf{S}$ staining, whereas only the large inclusions coimmunostained positively for phosphorylated serine 129-aSYN. Neither aSYN-positive inclusions nor small aggregates were detected in cells treated with the column flow-through. The crossed lines indicate the positions of the xz- and yz-planes. B, Double-immunolabeling studies demonstrated that the juxtanuclear large inclusions co-localized with $y$-tubulin, peripherin, and/or vimentin, which are known markers of the aggresome (a and $\mathbf{b}$ ). The aSYN-positive inclusion bodies in the KG1C cells (b) were co-localized with TPPP/p25a, a known marker for GCI in MSA. C, The formation of aSYN-positive cytoplasmic inclusions (arrowhead) was also confirmed in primary rat cortical neurons treated under the same condition. No visible aSYN-positive inclusions were detected in the mock-treated cells. $\mathbf{D}$, After aSYN exposure, the incidence of perinuclear inclusions in both the SH-SY5Y and KG1C cells increased in a time-dependent manner, reaching 35\% and 24\%, respectively, at 24 hours. Data are expressed as the mean \pm standard errors. The immunostaining was performed three times and exhibited consistent results. Scale bar: 10.0 um.

involved in clathrin-mediated endocytosis [41]. Dynamin 1 is highly expressed in the nervous system, whereas dynamin 2 is ubiquitously expressed in all tissues $[42,43]$. To investigate the functional roles of dynamin GTPases in the incorporation of $\alpha \mathrm{SYN}$, we examined the expression profile of dynamin isoforms in neuronal and oligodendroglial cells (Figure 4A). As shown by immunoblotting, dynamin 2 was widely expressed in both types of cells, whereas dynamin 1 was strongly expressed only in the dopaminergic neuronal cells. However, the expression of dynamin 1 was weak (MO3.13) or absent (KG1C) in cells of the oligodendroglial lineage. It is known that several selective serotonin reuptake inhibitors (SSRIs) also inhibit dynamin GTPases, which suggests the influence of a class effect. Among the dynamin inhibitors thus far examined, sertraline $\left(\right.$ Zoloft $\left.^{\circledR}\right)$, a second-generation SSRI, exhibited the strongest effect against both dynamin 1 and $2[41,43]$. We found that the pharmacological inhibition of dynamin GTPase activity by sertraline treatment $(50 \mathrm{mM}$ stock in DMSO with a working concentration of $0-10 \mu \mathrm{M}$, Sigma) prevented $\alpha$ SYN uptake by SH-SY5Y and KG1C cells in a dose-dependent manner (Figure 4B (a) and (b), respectively). Both cells types were treated with $5 \mu \mathrm{M} \alpha \mathrm{SYN}$ for 30 min with varying concentrations of sertraline as indicated. Consistent with this result, the inhibition of dynamin 1 through the use of a K44A dominant-negative (DN) mutant or small interference RNA (siRNA) resulted in a considerable decrease in $\alpha \mathrm{SYN}$ incorporation into $\mathrm{SH}$ SY5Y cells (Figure 4C (a) and (b), respectively). In addition, both $\alpha$ SYN monomers and SDS-stable HMW oligomers were increased in the cells overexpressing wild-type (wt) dynamin 1. The control experiment, which was not exposed to recombinant $\alpha \mathrm{SYN}$, demonstrated that dynamin 1 manipulation did not affect the expression level of endogenous $\alpha \mathrm{SYN}$ in the SH-SY5Y cells.

\section{Sertraline treatment inhibited the neuron-to-neuron and neuron-to-oligodendroglia transmission of a-synuclein in co-culture models}

To test whether sertraline could prevent the cell-to-cell spread of $\alpha \mathrm{SYN}$, we performed co-culture experiments. For this purpose, SH-SY5Y cells overexpressing N-terminal
mCherry-tagged $\alpha$ SYN (donor cells) were co-cultured with PC12 neuronal or MO3.13 oligodendroglial cells stably expressing Enhanced Green Fluorescence Protein (EGFP, acceptor cells), in the presence or absence of $10 \mu \mathrm{M}$ sertraline. The mCherry fluorophore was used to trace the donor-derived $\alpha S Y N$ protein. After 72 hours of co-culture, the transmission of mCherry- $\alpha \mathrm{SYN}$ from the donor cells to the acceptor PC12 and MO3.13 cells was detected, confirming the uptake of mCherry- $\alpha \mathrm{SYN}$ secreted from donor cells (Figure 5A). The spatial distribution detail of the mCherry fluorescence in donor cells was confirmed by orthogonal reconstructions from confocal z-stacks in the $\mathrm{xz}$ and yz-planes. Co-culture experiments using donor cells expressing mCherry- $\alpha \mathrm{SYN}$ showed that the percentage of acceptor cells with inclusions were 4.2\% (PC12) and 3.8\% (MO3.13), which was much higher than the percentage of the inclusion-positive cells (under $0.2 \%$ in both cell lines) from the co-culture with mCherry-expressing donor cells (Figure 5A and B). The addition of sertraline to the culture medium reduced the amount of incorporated mCherry- $\alpha S Y N$ in the acceptor cells, whereas this effect was not observed in the acceptor cells co-cultured with mCherry-expressing donor cells (Figure 5B). We confirmed that the sertraline treatment did not affect the secretion of mCherry- $\alpha \mathrm{SYN}$ from the donor SH-SY5Y cells (Figure $5 \mathrm{C}$ ). It should be noted that the extracellular mCherry- $\alpha S Y N$ released into culture media seems to be significantly lower than the recombinant $\alpha \mathrm{SYN}$ used in the previous experiments. We hypothesize that this is the reason for the relatively low internalization of mCherry- $\alpha S Y N$ in the acceptor cells of co-cultures compared to the level of inclusion formation in the cells exposed to recombinant $\alpha \mathrm{SYN}$. Together, these results suggest that the endocytic process contributes significantly to the neuronal as well as oligodendroglial uptake of $\alpha \mathrm{SYN}$.

\section{Discussion}

Although $\alpha \mathrm{SYN}$ is generally located in the cytoplasm, several studies have demonstrated that $\alpha S Y N$ has an affinity for phospholipids and vesicles $[44,45]$. In addition, $\alpha S Y N$ is known to be delivered to the plasma membrane 


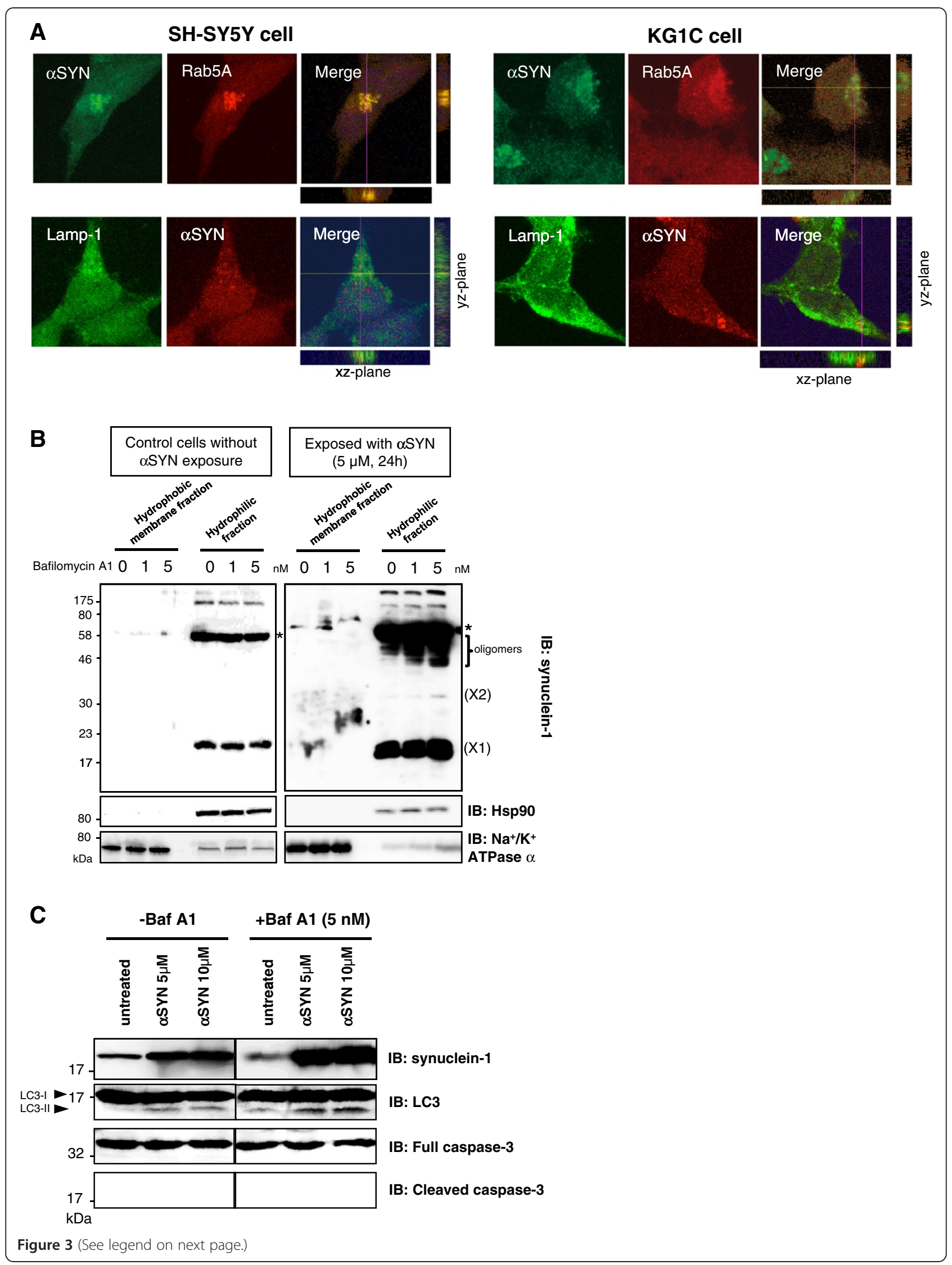


(See figure on previous page.)

Figure 3 Lysosomal inhibition facilitates a-synuclein oligomer formation and impairs autophagic flux. A, A portion of the aSYN-positive aggregates found in the aSYN-treated SH-SY5Y cells (5 $\mu \mathrm{M}$ recombinant aSYN for 24 hours) showed partial co-localization with markers of early endosomes (Rab5A) and lysosomes (Lamp-1). The crossed lines indicate the positions of the xz- and yz-planes. Immunostaining was performed three times and exhibited consistent results. Size bar: $10.0 \mu \mathrm{m}$. B, Pretreatment of the cells with bafilomycin A1 (0-5 nM) increased the

intracellular accumulation of the aSYN oligomers (X2 and higher) in a dose-dependent manner. Furthermore, this increase was mainly observed in the hydrophilic fractions of the aSYN-exposed cells, whereas the level of the aSYN monomer (X1) was unchanged. Fifty micrograms of lysates were analyzed by immunoblotting and the blot was probed with an anti-aSYN Ab. Hsp90 and Na $/ \mathrm{K}^{+}$ATPase a were used as markers for the cytosol and the plasma membrane, respectively. The asterisk indicates the non-specific band. C, In the aSYN-exposed SH-SY5Y cells (5 $\mu$ M recombinant aSYN for 24 hours), bafilomycin (5 nM) treatment augmented the induction of the LC3-II protein, whereas no cleaved fragments of caspase-3 were detected. Representative western blots from three independent experiments are presented.

through its interactions with the endoplasmic reticulum (ER)-Golgi secretory pathway [46]. Furthermore, increasing evidence has suggested that nanomolar concentrations of $\alpha S Y N$ can be found in neuronal culture medium, as well as in body fluids such as plasma and cerebrospinal fluid $[47,48]$. The secreted monomeric and oligomeric forms of $\alpha S Y N$ were shown to re-enter neighboring cells, resulting in various cytotoxic effects, such as the production of reactive oxygen species, the generation of a glial cell inflammatory response [18,21], and synaptic malfunction [20]. In the present study, we showed that, in cultured neuronal and oligodendroglial cells, the incorporated $\alpha \mathrm{SYN}$ oligomers were assembled into SDS-stable HMW oligomers and could form LBand GCI-like cytoplasmic inclusions. Except for KG1C cells, which do not express endogenous $\alpha \mathrm{SYN}$, it is possible that the internalized recombinant $\alpha S Y N$ may be entangled with endogenous $\alpha S Y N$, and the assembled HMW oligomers in the SH-SY5Y neuronal cells may consist of both endogenous and recombinant $\alpha S Y N$. Consistent with a previous study, we confirmed that most of the internalized $\alpha \mathrm{SYN}$ was located within the intracellular soluble fraction rather than the membrane fraction, indicating that extracellular $\alpha S Y N$ rapidly crosses the cellular membrane [18]. Furthermore, wildtype $\alpha \mathrm{SYN}$ has been shown to be degraded by lysosomes through chaperone-mediated autophagy, and decreased lysosomal function has also been observed in PD patients [49-52]. In agreement with this result, we detected internalized $\alpha S Y N$ in the endosomal compartment, where it was eventually degraded by the lysosomes. Our data showed that lysosomal inhibition impairs the autophagic flux in $\alpha S Y N$-treated neuronal and oligodendroglial cells. This observation strongly suggests that proper lysosomal machinery is required for the clearance of the incorporated $\alpha \mathrm{SYN}$ oligomers and is therefore indispensable for the maintenance of cellular homeostasis.

In addition to the Lewy pathology in PD, the presence of oligodendrocytic $\alpha$ SYN deposition, i.e., GCI, in MSA has attracted a significant amount of attention [29,53-55]. However, regarding the pathogenesis of MSA, it remains unclear why $\alpha \mathrm{SYN}$ accumulates in an oligodendrocytes, which do not normally express endogenous $\alpha \mathrm{SYN}$ [28]. It is possible that $\alpha \mathrm{SYN}$ expression may be upregulated and/or inefficiently degraded in affected oligodendrocytes. Alternatively, it is plausible that oligodendrocytes may actively take up $\alpha \mathrm{SYN}$ molecules derived from neurons. Indeed, endocytosis regulatory proteins such as Rab5 and Rabaptin-5 are known constituents of GCIs [56]. It is also possible that an intrinsic protein, such as $\mathrm{TPPP} / \mathrm{p} 25 \alpha$, may promote the aggregation of internalized $\alpha \mathrm{SYN}$ within oligodendroglia $[34,57,58]$. Interestingly, the prion-like hypothesis supports the possibility that aberrant oligodendroglial expression of $\alpha S Y N$ may have an ectopic origin. Our study provides the first concrete evidence that extracellular $\alpha \mathrm{SYN}$ can be incorporated and assembled into HMW oligomers and inclusions that mimic GCIs in cultured oligodendrocytes. In proteinfolding diseases, protein misfolding and aggregation are thought to follow a 'seeding-nucleation' mechanism [59-61], whereby misfolded $\alpha S Y N$ is transmitted from a LB-bearing donor cell to a neighboring recipient cell and can act as a template for the conversion of native, unfolded $\alpha S Y N$ into a $\beta$-sheet-rich conformation within the recipient cell. However, given that cultured oligodendroglial cells without inherent $\alpha S Y N$ expression can import extracellular $\alpha \mathrm{SYN}$ and form HMW oligomers, the existence of endogenous $\alpha \mathrm{SYN}$ may not be a prerequisite for the buildup of $\alpha \mathrm{SYN}$ aggregates in the recipient cells.

The precise mechanisms by which the intercellular transmission of $\alpha S Y N$ occurs remain controversial. Lee and colleagues implicated exocytosis as a plausible mechanism for $\alpha S Y N$ release from cultured neuronal cells because its release was effectively blocked under low-temperature conditions [39]. As brefeldin A, an inhibitor of ER-Golgi-dependent exocytosis, is ineffective at preventing the secretion of nascent $\alpha \mathrm{SYN}$ secretion by MES cells, $\alpha S Y N$ exocytosis is thought to rely on an unconventional exocytic pathway [62]. Intriguingly, the small GTPase Rab5, which is a known marker of early endosomes, is critical for the endocytosis of exogenous $\alpha S Y N$ into neuronal cells [18]. In a yeast model, the A30P mutant $\alpha$ SYN was shown to bind the endocytic 


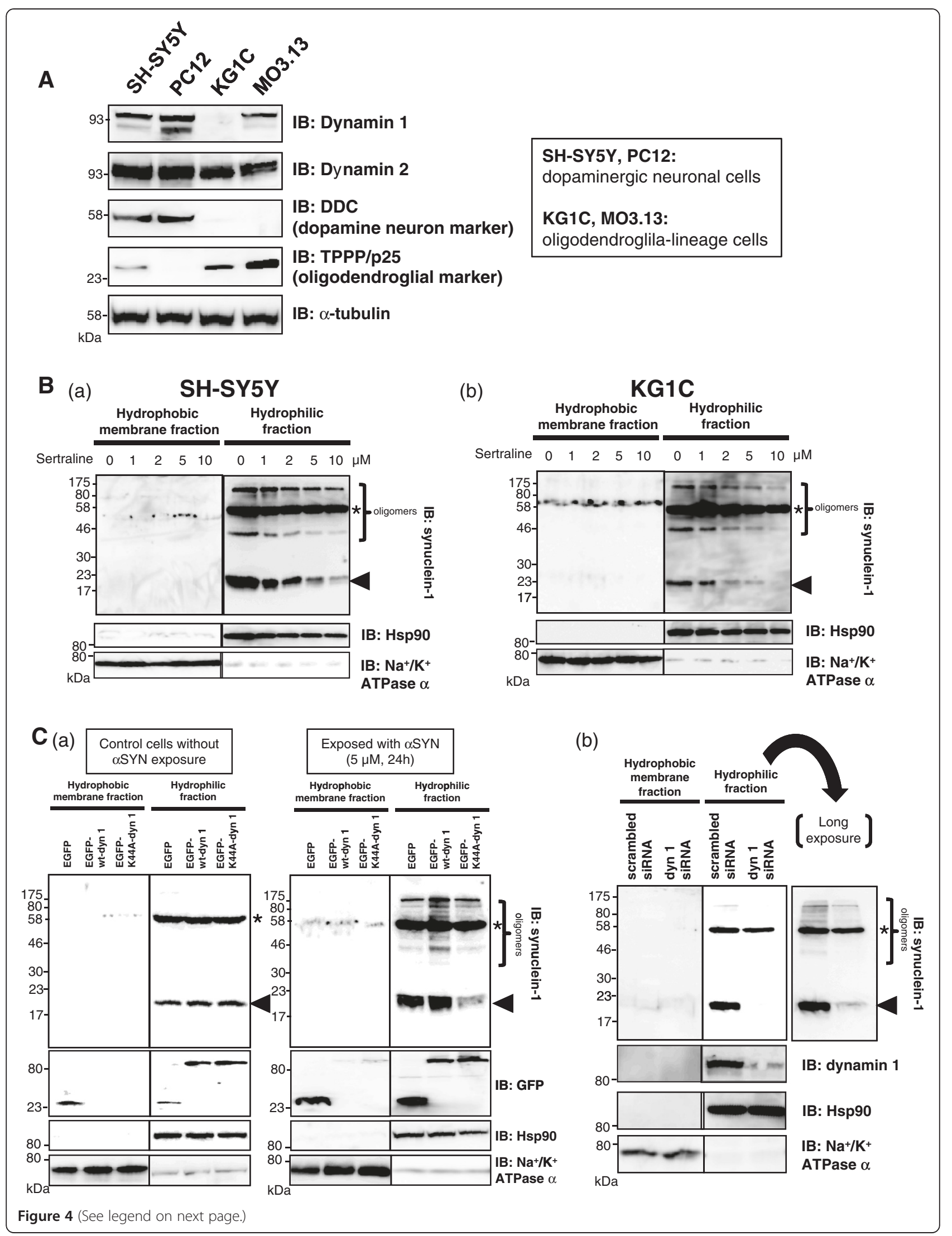


(See figure on previous page.)

Figure 4 The inhibition of dynamin GTPases decreases the internalization of a-synuclein by neuronal and oligodendroglial cells. A, The expression profile of various dynamin isoforms across neuronal and oligodendroglial cells. Dynamin 2 was widely expressed in both types of cells, whereas dynamin 1 was strongly expressed in dopaminergic neuronal cells. However, the expression of dynamin 1 was weak (MO3.13) or absent (KGIC) in cells of the oligodendroglial lineage. Equal loading was confirmed using a-tubulin as control. B, The pharmacological inhibition of dynamin GTPase activity via sertraline treatment (0-10 $\mu \mathrm{M}$ for $30 \mathrm{~min}$ ) dose-dependently prevented both monomeric (arrowhead) and oligomeric aSYN accumulation in SH-SY5Y (a) and KG1C (b) cells. Both cells were treated with $5 \mu \mathrm{M}$ aSYN for 30 min with different concentrations of sertraline, as indicated. The control cells were treated with solvent (0.1\% DMSO) alone. Fifty micrograms of each lysate was analyzed by immunoblotting, and the blot was probed with an anti-aSYN Ab. Hsp90 and $\mathrm{Na}^{+} / \mathrm{K}^{+}$ATPase a were used as markers for the cytosol and the plasma membrane, respectively. The asterisk indicates the non-specific band. C, Consistent with the results shown in Figure 4B, the inhibition of dynamin 1 through the use of either the K44A DN mutant (a) or siRNA (b) resulted in a marked reduction of internalized aSYN in SH-SY5Y cells. Cells were treated with $5 \mu \mathrm{M}$ aSYN (for $30 \mathrm{~min}$ ) 48 hours after either the DN-dynamin1 transfection or the siRNA silencing of dynamin 1. Note that the aSYN monomer and the SDS-stable HMW oligomers were increased in cells overexpressing wild-type dynamin 1. Representative immunoblots from three independent experiments are shown.

cargo-transport protein YPP1 at the plasma membrane, which led to the budding of endocytic vesicles via receptor-mediated endocytosis and the subsequent targeting of this form of $\alpha \mathrm{SYN}$ to the vacuole for degradation [63]. Furthermore, previous studies by our lab and others have demonstrated that internalized $\alpha S Y N$ is secreted from neurons via a process that is modulated by the recycling endosome regulator Rab11a [64,65]. In the case of prion disease, both the normal cellular prion protein (PrPc) and the abnormally folded pathogenic form (PrPsc) are associated with nanovesicles called 'exosomes' that are released from non-neuronal and neuronal cells $[66,67]$. However, the involvement of the exosomal vesicle in $\alpha \mathrm{SYN}$ secretion remains unclear. $\alpha S Y N$ has been shown to be secreted by the exosome, and exosome-containing conditioned medium can induce neuronal cell death $[68,69]$. In contrast, we recently demonstrated that extracellular $\alpha S Y N$ was mainly detected in the supernatant fraction rather than in the exosome-containing pellets obtained from neuronal culture medium or CSF [64]. Moreover, we found that the perturbation of exosome formation by a DN mutant of vacuolar protein sorting 4. (VPS4) not only interfered with lysosomal targeting of $\alpha \mathrm{SYN}$ but also facilitated $\alpha \mathrm{SYN}$ secretion [64].

Regardless of the mechanisms involved in $\alpha \mathrm{SYN}$ secretion, there is evidence to support the uptake of extracellular $\alpha$ SYN by neighboring cells, which subsequently facilitates aggregate formation. Previous reports have suggested that the internalization of $\alpha \mathrm{SYN}$ oligomers may be mediated by the endocytic process; the overexpression of a DN-dynamin effectively reduced the extent of incorporated $\alpha \mathrm{SYN}$ aggregates in cultured cell lines $[21,39]$. Furthermore, the inhibition of endocytosis by monodansylcadaverine and dynasore has also been shown to decrease $\alpha S Y N$ uptake both in vitro and in vivo [22]. Coincubation of $\alpha S Y N$ pre-formed fibrils with WGA enhances the $\alpha \mathrm{SYN}$ pathology in neuronal cells, indicating adsorptive-mediated endocytosis as the potential mechanism of $\alpha \mathrm{SYN}$ internalization [20]. The importance of the endocytic process in the uptake of extracellular $\alpha \mathrm{SYN}$ is further supported by our findings showing that genetic as well as pharmacological disruption of the dynamin GTPases through the administration of sertraline, a widely used antidepressant, significantly decreased the internalization and translocation of $\alpha \mathrm{SYN}$. It should also be noted that the concentration of sertraline used in our study $(10 \mu \mathrm{M}=3 \mu \mathrm{g} / \mathrm{ml})$ is comparable to the concentrations observed to be therapeutically effective within the CSF and brain $(2 \mu \mathrm{g} / \mathrm{ml})$ for its antidepressant effects [70]. In fact, neuropsychiatric manifestations such as depression, apathy, and anxiety are frequently encountered as non-motor symptoms in PD patients [71,72]. SSRIs are currently used as a first-line therapy for PD-associated depression [73]. Thus, the identification of novel therapeutic uses for sertraline not only provides a strategy focused on the prevention of the pathological propagation of $\alpha \mathrm{SYN}$ but also has the advantage of utilizing time-tested drugs for the benefit of patients. A recent study has shown that the first SSRI, fluoxetine, ameliorated behavioral and neuropathological deficits in an MSA mouse model [74]. They concluded that the protective effect of fluoxetine might be attributed to the increased level of neurotrophic factors and/or the activation of the ERK signaling pathway; however, the reduction of $\alpha S Y N$-propagation through the inhibition of dynamin may be another underlying mechanism. Indeed, tricyclic antidepressants, which are also known to inhibit dynamin GTPases, have been shown to slow disease progression in PD $[41,75]$. In the case of MSA, a German group has reported the effectiveness of paroxetine in a small, short-term trial with 19 MSA patients [76]. In this study, motor disabilities and dysarthria were significantly improved compared with the placebo group. It is also interesting to note that paroxetine may prevent the glottis stenosis in MSA patients [77]. Further investigations with larger samples are necessary to assess the long-term safety and effectiveness of SSRI treatment in MSA. We are currently awaiting for the outcome of a double-blind, multicenter trial using fluoxetine for the 
A

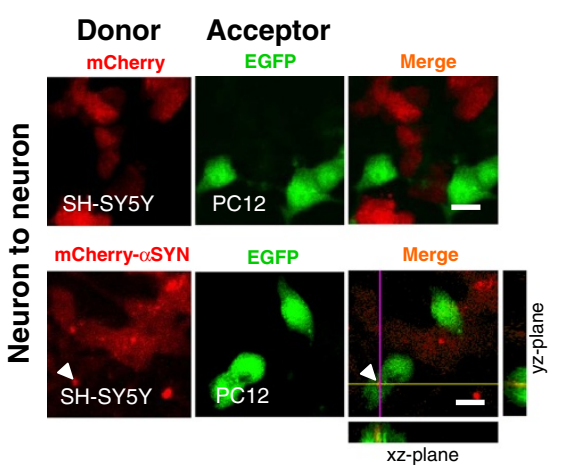

B

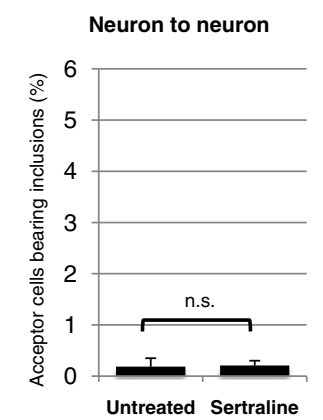

mCherry

Neuron to oligodendroglia

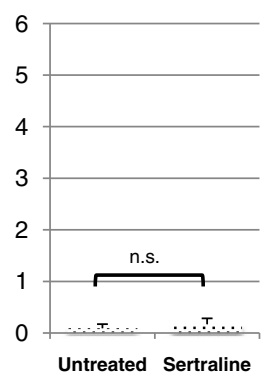

C

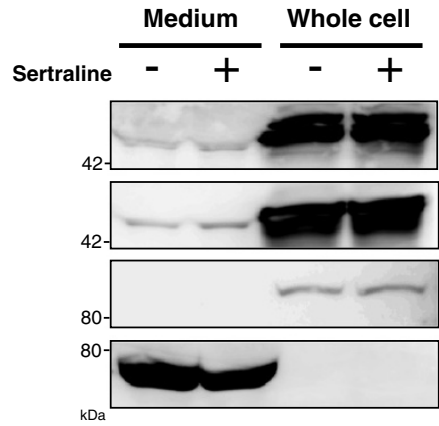

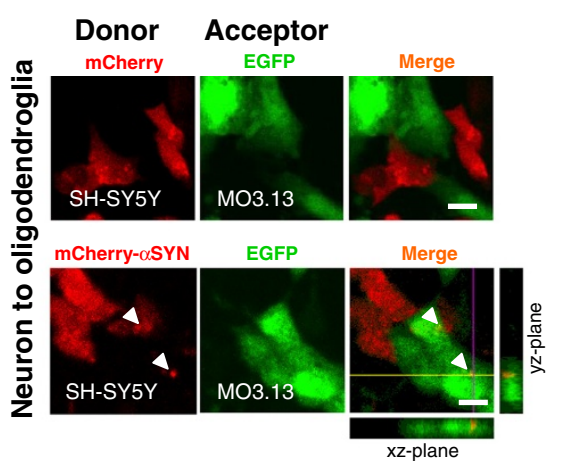

mCherry- $\alpha$ SYN

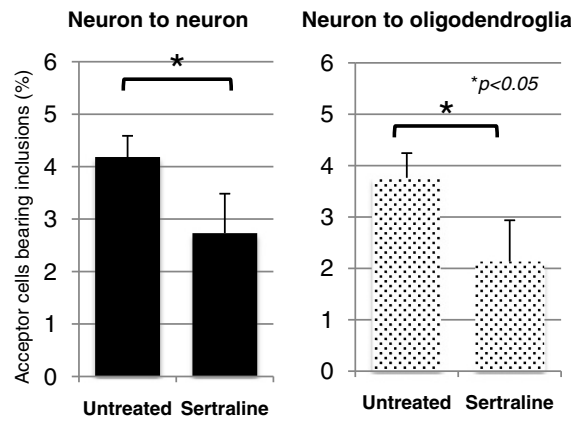

Figure 5 Sertraline inhibits the neuron-to-neuron and neuron-to-oligodendroglia transmission of a-synuclein in co-culture models. A, SH-SY5Y cells overexpressing mCherry or N-terminally mCherry-tagged aSYN (donor cells) were co-cultured with PC12 neuronal or MO3.13 oligodendroglial cells stably expressing EGFP (acceptor cells) in the presence or absence of $10 \mu \mathrm{M}$ sertraline. Vehicle-only-transfected cells were treated with solvent ( $0.1 \%$ DMSO) only. The mCherry fluorophore was used to trace the donor-derived aSYN protein. After 72 hours of co-culture, the transmission of mCherry-aSYN from the donor cells to the acceptor PC12 as well as MO3.13 cells was detected, confirming the uptake of mCherry-aSYN secreted from the donor cells. The arrowhead indicates the transferred mCherry-aSYN-positive aggregates in the acceptor cells. The crossed lines indicate the positions of the xz- and yz-planes. B, A co-culture experiment using donor cells expressing mCherry-aSYN showed that the percentage of acceptor cells with inclusions were 4.2\% (PC12) and 3.8\% (MO3.13), which is much higher than the percentage of inclusion-positive cells (under $0.2 \%$ in both cell lines) co-cultured with mCherry-expressing donor cells. The addition of sertraline to the culture medium reduced the incorporation of mCherry-aSYN into the acceptor cells ${ }^{*} p<0.05$ ), whereas this effect was not observed in the acceptor cells that were co-cultured with the mCherry-expressing donor cells. To quantify the mCherry-positive inclusions in the acceptor cells, the total number of cells containing aggregates was counted per 250-300 cells within five randomly selected fields. From this value, the percentages of cells with red-fluorescent inclusions were calculated. Pooled data from four independent experiments were statistically analyzed. Data are presented as the mean \pm standard errors. $\mathbf{C}$, Western blot analysis demonstrated that sertraline treatment did not affect the secretion of the mCherry-aSYN from the donor SH-SY5Y cells. BSA and Hsp90 were used as markers of the culture medium and the cytosolic proteins, respectively. Each immunoblot was performed at least three times and the replicates yielded similar results. 
treatment of MSA (MSA-Fluox) being conducted in France [78].

In summary, we demonstrated that $\alpha \mathrm{SYN}$ was taken up by neuronal and oligodendroglial cells, assembled into HMW oligomers, and formed cytoplasmic inclusions. Furthermore, we have provided evidence that $\alpha S Y N$ uptake by neuronal and oligodendroglial cells is regulated by dynamin GTPases, which implies a role for the endocytic process in this activity. The importance of the vesicular trafficking machinery in the pathogenesis of PD is also highlighted by recent findings that a mutation in the VPS35 gene, which encodes a retromer complex involved in the retrograde transport of proteins from the endosome to the trans-Golgi network, can cause late-onset familial PD [79-81]. Furthermore, the prevention of $\alpha \mathrm{SYN}$-mediated pathology by sertraline is a potentially promising method for the treatment of PD and other synucleinopathies. Thus, defining the precise mode of intercellular $\alpha \mathrm{SYN}$ transmission will shed light on the pathogenic mechanisms involved in synucleinopathies, and this research may pave the way for the identification of novel targets for therapeutic intervention in other neurodegenerative diseases.

\section{Methods}

\section{Plasmid construction and preparation}

For the bacterial expression of the GST- $\alpha$ SYN fusion protein, human $\alpha S Y N$ cDNA was subcloned into the SalI and NotI restriction sites of the pGEX6P-1 vector (GE Healthcare Life Sciences, Piscataway, NJ), which encodes an N-terminal GST fusion tag that is cleavable by a human rhinovirus $3 \mathrm{C}$ proteinase recognition site (Leu-Glu-Val-Leu-Phe-Gln-Gly-Pro, referred to as the PreScission $^{\circledR}$ site). An N-terminal mCherry-tagged human wt- $\alpha \mathrm{SYN}$ cDNA was introduced into the KpnI and $\mathrm{XhoI}$ sites of the pcDNA3.1+ expression vector (Life Technologies/Invitrogen, Carlsbad, CA). The pEGFP-C1 eukaryotic expression plasmids (Clontech, Mountain View, CA) encoding the EGFP-tagged human wt and DN mutant K44A dynamin 1 were kindly provided by Dr. Hiroshi Miyoshi at the St. Marianna University School of Medicine in Kawasaki, Japan. Plasmid DNA used for transfection was prepared with the Genopure Plasmid Maxi Kit (Roche, Basel, Switzerland). The fidelity and orientation of the expression constructs were confirmed by restriction digestion and nucleotide sequencing analyses.

\section{Recombinant a-synuclein purification}

The GST- $\alpha$ SYN fusion construct (pGEX6P-1/ $\alpha$ SYN) was transformed into the BL21(DE3)pLysS E. coli strain for protein expression. The transformed bacteria were grown in LB medium containing $100 \mu \mathrm{g} / \mathrm{ml}$ ampicillin and $35 \mu \mathrm{g} / \mathrm{ml}$ chloramphenicol (for pLysS) at $37^{\circ} \mathrm{C}$ until reaching an $A_{600}$ of 0.4 . The bacteria were then cultured for an additional 5 hours following induction with $0.5 \mathrm{mM}$ IPTG. The bacteria were harvested by centrifugation, resuspended in ice-cold PBS ( $\mathrm{pH} 7.4$ ), and disrupted by ultrasonication (Smurt NR-50, Microtec, Chiba, Japan). After removal of the cell debris, the supernatant was loaded onto a glutathione-Sepharose 4B column (GE Healthcare) equilibrated with PBS. The GST- $\alpha$ SYN fusion protein was washed with PBS three times and was then eluted with $10 \mathrm{mM}$ glutathione elution buffer. The final eluate that flowed through the column was collected as the control specimen and was further dialyzed against PBS overnight. Next, the GST tag was cleaved overnight at $4^{\circ} \mathrm{C}$ on a carousel in the presence of the PreScission ${ }^{\circledR}$ protease (2 units for $100 \mu \mathrm{g}$ fusion protein, GE Healthcare). After cleavage, the sample was re-loaded onto the glutathioneSepharose 4B column, and the flowthrough containing the tag-free $\alpha S Y N$ was collected. The purity and the identity of the recombinant $\alpha S Y N$ were verified by $\mathrm{CBB}$ staining and western blot analysis. The recombinant $\beta S Y N$ and $\gamma \mathrm{SYN}$, as well as A30P and A53T mutants of $\alpha \mathrm{SYN}$, were purchased from ATGen Co., Ltd. (Gyeonggi-do, Korea).

\section{Cell culture and plasmid transfection}

Dopaminergic neuronal cells (human SH-SY5Y and rat PC12) and human cells of oligodendroglia-lineage (KG1C and MO3.13) were maintained in Dulbecco's Modified Eagle's Medium (DMEM; Life Technologies/ GIBCO, Carlsbad, CA) containing $4.5 \mathrm{~g} / \mathrm{l}$ glucose, 2 mM L-glutamine (Life Technologies) and 10\% FBS (PAA Laboratories, Pasching, Austria) at a temperature of $37^{\circ} \mathrm{C}$ under conditions of humidified $5 \% \mathrm{CO}_{2}$ /air. The SH-SY5Y cells were purchased from American Type Culture Collection (ATCC, Vienna, VA). The PC12 cells were kindly given to us by Dr. Katsutoshi Furukawa, Department of Geriatrics and Gerontology, Tohoku University, Sendai, Japan. The KG1C and MO3.13 cells were purchased from RIKEN Cell Bank (Tsukuba, Japan) and Cosmo Bio (Tokyo, Japan), Respectively. Plasmid DNAs $\left(2 \mu \mathrm{g}\right.$ DNA for $1.5 \times 10^{6}$ cells) were introduced into the SH-SY5Y cells using the 4D-Nucleofector ${ }^{\mathrm{TM}}$ device with the CA-137 program (LONZA AG, Cologne, Germany). The cells were harvested 48 hours post-transfection unless otherwise stated. For the suppression of dynamin GTPases, cells were treated with $5 \mu \mathrm{M} \alpha \mathrm{SYN}$ for $30 \mathrm{~min}$ with varying concentration of sertraline as indicated. Likewise, the SH-SY5Y cells were treated with $5 \mu \mathrm{M}$ $\alpha S Y N$ (for $30 \mathrm{~min}$ ) 48 hours after transfection with the DN-dynamin1 or the siRNA silencing of dynamin 1 . Stable transfection of mcherry- $\alpha$ SYN or EGFP in the cultured cells was achieved using the FuGENE $\mathrm{HD}^{\circledR}$ 
Transfection Reagent (Roche) according to the manufacturer's instructions. For the stable transfection of mcherry- $\alpha$ SYN or EGFP, the transfected cells were maintained under selective pressure with $300 \mu \mathrm{g} / \mathrm{ml} \mathrm{G418}$ sulfate (InvivoGen, San Diego, CA).

\section{Primary cortical neuron culture}

Primary cultures of rat cortical neurons were prepared according to a previous method, with slight modifications [82]. The dissociated cortical neurons were plated at a density of $0.5 \times 10^{6}$ cells on a poly-D-lysine-coated disc (Sumilon Celldesk LF, Sumitomo Bakelite Co., Ltd., Tokyo, Japan) in a 24-well plate and cultured in Neurobasal A (Life Technologies/GIBCO) medium supplemented with 2\% B27 (Life Technologies/GIBCO), $25 \mathrm{mM}$ glutamate, $18 \mathrm{mM}$ glucose and $0.5 \mathrm{mM}$ L-glutamine. Half of the culture medium was replaced with fresh medium excluding glutamate every 3 days. Six days after the initiation of the culture, cells were exposed to $5 \mu \mathrm{M}$ recombinant $\alpha S Y N$ for 24 hours and were then subjected to immunocytochemical analysis.

siRNA knockdown of endogenous dynamin in SH-SY5Y cells To suppress endogenous dynamin 1 expression in cultured neuronal cells, siRNA specifically targeting human dynamin 1 (sc-43737) was used; this specific siRNA and a scrambled control siRNA (sc-36869) were purchased from Santa Cruz Biotechnology (Santa Cruz, CA). SHSY5Y cells in log-phase growth were nucleofected with target-specific or control-scrambled siRNAs (300 nM for $2 \times 10^{6}$ cells) using the 4D-Nucleofector device with the CA-137 program and SF solution (LONZA AG). Seventy-two hours after gene silencing, the cells were harvested and subjected to further studies.

\section{Co-culture experiments}

For the mixed culture of $\alpha \mathrm{SYN}$ donor and acceptor cells, SH-SY5Y neuronal cells overexpressing mCherry or mCherry-tagged $\alpha$ SYN $\left(2 \times 10^{5}\right.$ donor cells in a $3.5-\mathrm{cm}$ dish) were co-cultured with neuronal PC12 or oligodendroglial MO3.13 cells stably expressing EGFP $\left(2 \times 10^{5}\right.$ acceptor cells in a $3.5-\mathrm{cm}$ dish $)$ in culture medium with or without $10 \mu \mathrm{M}$ sertraline for 5 days. Incorporated mCherry- $\alpha \mathrm{SYN}$ in the acceptor cells was evaluated using a FluoView ${ }^{\mathrm{TM}}$ FV300 confocal microscope system equipped with HeNe-Green (543 nm) and Ar (488 nm) laser units (Olympus, Tokyo, Japan). To quantify the mCherry-positive cytoplasmic inclusions in the acceptor cells, the total number of cells containing aggregates was counted per 250-300 cells from each of five randomly selected fields. From this, the percentages of cells with red-fluorescent inclusions were calculated. Data pooled from four independent experiments were statistically analyzed with the Student's $t$-test. The data were presented as the mean \pm standard errors. For the double labeling experiments, the images were collected using a single excitation for each wavelength individually and were then merged using Fluoview image analyzing software (version 4.1, Olympus).

\section{Cell fractionation and western immunoblot analysis}

Mechanically harvested cells were washed twice with ice-cold PBS. Next, the hydrophobic membrane fraction and hydrophilic fraction were prepared using the Mem-PER ${ }^{\circledR}$ Eukaryotic Membrane Protein Extraction Reagent kit (Thermo Scientific, Waltham, MA) according to the manufacturer's instructions. In some experiments, the cells were pretreated with bafilomycin A1 (0-5 nM for 24 hours) or sertraline (0-10 $\mu \mathrm{M}$ for $30 \mathrm{~min})$ with or without exposure to $\alpha S Y N$. Successful separation of the hydrophilic fraction from the membrane fraction was verified by immunoblot analyses using Abs against the cytosolic Hsp90 and the plasma membrane localized protein $\mathrm{Na}^{+} / \mathrm{K}^{+}$ATPase $\alpha$, respectively. In some experiments, cells were directly solubilized in radio-immunoprecipitation assay (RIPA) buffer (1\% NP-40, 0.5\% deoxycholate, $0.1 \%$ SDS, $1 \mathrm{mM}$ EDTA, $10 \mathrm{mM}$ sodium pyrophosphate, $50 \mathrm{mM}$ sodium fluoride, $1 \mathrm{mM}$ sodium orthovanadate, $150 \mathrm{mM}$ sodium chloride, $50 \mathrm{mM}$ Tris- $\mathrm{HCl}(\mathrm{pH}$ 8.0) plus $1 \mathrm{x}$ Cømplete $^{\circledR}$ protease inhibitor cocktail; Roche). Samples containing $50 \mu \mathrm{g}$ total protein were electrophoresed on SDS-polyacrylamide gels (12.5\%) and transferred onto polyvinylidene difluoride (PVDF) membranes (Immobilon-P; Merck Millipore, Billerica, MA). Native-PAGE was performed on $10-20 \%$ polyacrylamide gradient gels, according to the standard protocol. In some experiments, the separated proteins were visualized by staining with CBB R-250 (MP Biomedicals, Solon, OH). After blocking with 5\% (w/v) nonfat dry milk (Wako Pure Chemical Industries, Ltd., Osaka, Japan) in Tris-buffered saline with $0.1 \%$ Tween 20 (TBST), the membranes were incubated with the following Abs: anti-synuclein-1 (63320, 1:1000; BD Bioscience, San Jose, CA), anti- $\alpha$ SYN (\#2628, 1:1000; CST, Danvers, MA), anti-GST (\#2625, 1:1000: CST), anti-LC3 (PM036, 1:1000; MBL, Nagoya, Japan), anti-caspase 3 (H-277, 1:2000; Santa Cruz), anti-cleaved caspase 3 (Asp 175, 1:1000; CST), antidynamin 1 (3G4B6, 1:1000; CST), anti-dynamin 2 (610263, 1:4000; BD Transduction Lab, Franklin Lakes, NJ), antidopa decarboxylase (DDC) (AB1569, 1:1000; Millipore), anti-TPPP/p25 $\alpha$ (EPR3315, 1:1000; Epitomics, Burlingame, CA), anti-GFP (M048-3, 1:2000; MBL) anti- $\mathrm{Na}^{+} / \mathrm{K}^{+}$ATPase $\alpha$ (D154-3, 1:20000; MBL), anti-Hsp90 (AC88, 1:2000; Stressgen, Farmingdale, NY), anti- $\alpha$-tubulin (clone DM1, 1:1000; Sigma) and anti-mCherry (5993, 1:1000; BioVision, Mountain View, CA). The primary antibody labeling was followed by the addition of HRP-conjugated secondary Abs (1:10000; Jackson ImmunoResearch, West Grove, PA). The bands were visualized with the Luminata ${ }^{\mathrm{TM}}$ Forte Western 
HRP substrate (Millipore), and the images were captured using the LAS-3000 mini image analyzer (Fujifilm, Tokyo, Japan). Immunoblotting was performed at least three times. In some experiments, the blots were scanned and densitometric analyses were performed using Image J (http://www. rsb.info.nih.gov/ij/) [83]. The intensity unit of the $\alpha \mathrm{SYN}$ monomer was divided by that of Hsp90. Data are expressed as the mean \pm standard errors.

\section{Immunofluorescence confocal microscopy}

Cells were fixed in $4 \%(\mathrm{w} / \mathrm{v})$ paraformaldehyde in PBS for $30 \mathrm{~min}$ and then permeabilized with $0.5 \%$ Triton $\mathrm{X}-100$ in PBS for 5 min. After blocking with 3\% normal goat serum (Wako Pure Chemical Industries) in PBS for $30 \mathrm{~min}$, the cells were incubated with the following primary antibodies: anti-synuclein-1 (1:1000; BD Bioscience), anti- $\alpha$ SYN (\#2628, 1:2000; CST), anti-Serine 129 phospho- $\alpha$ SYN (EP1526Y, 1:1000; Epitomics), anti- $\gamma$-tubulin (GTU-88, 1:4000; Sigma, St. Louis, MO), anti-peripherin (AB1530, 1:1000; Millipore-Chemicon), anti-vimentin (V9, 1:500; Sigma), anti-ubiquitin (P4D1, 1:1000; Santa Cruz), anti-MAP2 (\#4542, 1:1000; CST), anti-TPPP/p25 (EPR-3315, 1:1000; Epitomics), anti-Rab5A Ab (S-19, 1:1000; Santa Cruz) and anti-Lamp-1 (H4A3, 1:1000; DSHB, University of Iowa, USA). For thioflavin S staining, the coverslips were immersed in $0.03 \%(\mathrm{w} / \mathrm{v})$ thioflavin $\mathrm{S}$ (Sigma) solution for $5 \mathrm{~min}$ and were then extensively washed with $70 \%$ ethanol. Positive immunostaining was detected after a 1-hour incubation with Alexa 488- and Alexa 568-conjugated secondary Abs (1:4000; Life Technologies/Molecular Probes, Carlsbad, CA). Nuclei were counterstained with TO-PRO3 iodide (1:1000; Molecular Probes) and were pseudocolored in blue. The fluorescent images were analyzed with the FluoView FV300 confocal laser scanning microscope system (Olympus). The crossed lines indicate the positions of the $x z-$ and yz-planes. To quantify the $\alpha S Y N$-immunopositive inclusions, the total number of cells with any aggregates was counted across 250-300 cells in five randomly chosen fields. From this, the percentages of cells with inclusions were calculated. Pooled data from four independent experiments were statistically analyzed using the Student's $t$-test. The data are expressed as the mean \pm standard errors.

\section{Additional files}

Additional file 1: Figure S1. Analyses of internalized a-synuclein monomer in exposed cells. A, The densitometric analysis of monomeric aSYN in hydrophilic fraction prepared from aSYN-exposed SH-SY5Y (a and c) and KG1C cells (b). The intensity units of the aSYN monomer were normalized by dividing them by that of Hsp90. Data are expressed as the mean \pm standard errors. B, The GST-tagged aSYN $(5 \mu \mathrm{M})$ in the culture medium was time-dependently detected and shown to form HMW GSTimmunopositive oligomers and the HMW smear mainly in the hydrophilic fraction of the SH-SY5Y cells, demonstrating that the extracellular aSYN was internalized and oligomerized in the exposed cells. All immunoblottings were performed four times.

Additional file 2: Figure S2. The difference in a-synuclein internalization behavior among mammalian synuclein-family proteins. To evaluate the difference in the internalization behavior among the synuclein-family proteins, SH-SY5Y cells exposed to $5 \mu \mathrm{M} \mathrm{a-}, \beta$ - and $\gamma$ SYN, were fractionated and subjected to immunoblot analyses (right panel). Note that aSYN was exclusively internalized into the SH-SY5Y cells, whereas $\beta$ - and $Y$-SYN were not. Furthermore, the A30P and A53T mutations in aSYN strongly augmented the formation of the SDS-stable oligomers in the hydrophilic fraction when compared to those observed in the wt-aSYN-exposed cells. The specificity and sensitivity of each synuclein Ab were verified by immunoblotting using the lysates of HEK293T cells overexpressing Myc-tagged $a-, \beta$ - and $\gamma$-SYN, respectively (left panel). Representative immunoblots from three independent experiments are shown.

\section{Abbreviations}

aSYN: a-synuclein; $\beta S Y N$ : $\beta$-synuclein; $\gamma S Y N$ : $\gamma$-synuclein; LB: Lewy body; PD: Parkinson's disease; GCl: Glial cytoplasmic inclusion; MSA: Multiple system atrophy; SDS-PAGE: Sodium dodecyl sulfate-polyacrylamide gel electrophoresis; IPTG: Isopropyl $\beta$-D-1-thiogalactopyranoside; E. coli: Escherichia coli; CBB: Coomasie brilliant blue; HMW: High molecular weight; ER: Endoplasmic reticulum; TPPP/p25a: Tubulin polymerization promoting protein/p25a; WGA: Wheat germ agglutinin; PrP: Prion protein; VPS4: Vacuolar protein sorting 4; SSRI: Selective serotonin-reuptake inhibitor; EGFP: Enhanced Green Fluorescence Protein; wt: wild-type; DN: Dominant-negative; DMEM: Dulbecco's Modified Eagle's Medium; siRNA: Small interference RNA; RIPA: Radio-immunoprecipitation assay; PVDF: Polyvinylidene difluoride; TBST: Tris-buffered saline with 0.1\% Tween 20; Ab: Antibody; DDC: Dopa decarboxylase.

\section{Competing interests}

The authors declare that they have no competing interests.

\section{Authors' contributions}

$M K, T H, T B$, and EM performed the experiments. NS, AK, and AT analyzed the data. FCF, TS, MA, and YI contributed reagents/materials. MK and TH designed the study and wrote the paper. AT is the principal investigator. All authors read and approved the final manuscript.

\section{Acknowledgements}

This work was supported in part by a Grant-in-Aid for Scientific Research (C) (23591228), a Grant-in-Aid for Scientific Research (B) (24390219), a Grant-inAid for Exploratory Research (24659423) from The Ministry of Education, Culture, Sports, Science and Technology (MEXT), a Grant from the Research Committee for Ataxic Diseases, a Grant-in-Aid for Scientific Research on Innovative Areas (Brain Environment; 24111502) from the Ministry of Health, Labor, and Welfare, Japan, and a Grant from the Symposium on Catecholamine and Neurological Disorders, Japan. The funders had no role in study design, data collection and analysis, decision to publish, or preparation of the manuscript.

\section{Author details}

${ }^{1}$ Division of Neurology, Department of Neuroscience and Sensory Organs, Tohoku University Graduate School of Medicine, Sendai, Miyagi 980-8574, Japan. ${ }^{2}$ Department of Neuroscience, Mayo Clinic, 4500 San Pablo Road, Jacksonville, FL 32224, USA. ${ }^{3}$ Department of Neurology, Osaka University Graduate School of Medicine, Suita, Osaka 565-0871, Japan. ${ }^{4}$ National Center Hospital for Mental, Nervous, and Muscular Disorders, National Center of Neurology and Psychiatry (NCNP), Kodaira, Tokyo 187-8502, Japan.

Received: 5 March 2012 Accepted: 6 August 2012 Published: 14 August 2012

\section{References}

1. Baba M, Nakajo S, Tu PH, Tomita T, Nakaya K, Lee VM, Trojanowski JQ, Iwatsubo T: Aggregation of alpha-synuclein in Lewy bodies of sporadic Parkinson's disease and dementia with Lewy bodies. Am J Pathol 1998, 152:879-884. 
2. Hasegawa T, Matsuzaki M, Takeda A, Kikuchi A, Akita H, Perry G, Smith MA, Itoyama Y: Accelerated alpha-synuclein aggregation after differentiation of SH-SY5Y neuroblastoma cells. Brain Res 2004, 1013:51-59.

3. Spillantini MG, Schmidt ML, Lee VM, Trojanowski JQ, Jakes R, Goedert M: Alpha-synuclein in Lewy bodies. Nature 1997, 388:839-840.

4. Wakabayashi K, Matsumoto K, Takayama K, Yoshimoto M, Takahashi H: NACP, a presynaptic protein, immunoreactivity in Lewy bodies in Parkinson's disease. Neurosci Lett 1997, 239:45-48.

5. Wakabayashi K, Hayashi S, Kakita A, Yamada M, Toyoshima Y, Yoshimoto M, Takahashi H: Accumulation of alpha-synuclein/NACP is a cytopathological feature common to Lewy body disease and multiple system atrophy. Acta Neuropathol 1998, 96:445-452.

6. Sugeno N, Takeda A, Hasegawa T, Kobayashi M, Kikuchi A, Mori F, Wakabayashi K, Itoyama Y: Serine 129 phosphorylation of alpha -synuclein induces unfolded protein response-mediated cell death. J Biol Chem 2008, 283:23179-23188.

7. Furukawa K, Matsuzaki-Kobayashi M, Hasegawa T, Kikuchi A, Sugeno N, Itoyama Y, Wang Y, Yao PJ, Bushlin I, Takeda A: Plasma membrane ion permeability induced by mutant alpha-synuclein contributes to the degeneration of neural cells. J Neurochem 2006, 97:1071-1077.

8. Hasegawa T, Matsuzaki-Kobayashi M, Takeda A, Sugeno N, Kikuchi A, Furukawa K, Perry G, Smith MA, Itoyama Y: Alpha-synuclein facilitates the toxicity of oxidized catechol metabolites: implications for selective neurodegeneration in Parkinson's disease. FEBS Lett 2006, 580:2147-2152.

9. Kahle PJ: Alpha-Synucleinopathy models and human neuropathology: similarities and differences. Acta Neuropathol 2008, 115:87-95.

10. Takeda A, Hasegawa T, Matsuzaki-Kobayashi M, Sugeno N, Kikuchi A, Itoyama Y, Furukawa K: Mechanisms of neuronal death in synucleinopathy. J Biomed Biotechnol 2006, 2006:19365.

11. Iwai A, Masliah E, Yoshimoto M, Ge N, Flanagan L, de Silva HA, Kittel A, Saitoh T: The precursor protein of non-A beta component of Alzheimer's disease amyloid is a presynaptic protein of the central nervous system. Neuron 1995, 14:467-475.

12. Clayton DF, George JM: The synucleins: a family of proteins involved in synaptic function, plasticity, neurodegeneration and disease. Trends Neurosci 1998, 21:249-254.

13. Angot E, Steiner JA, Hansen C, Li JY, Brundin P: Are synucleinopathies prion-like disorders? Lancet Neurol 2010, 9:1128-1138.

14. Lee SJ, Desplats P, Sigurdson C, Tsigelny I, Masliah E: Cell-to-cell transmission of non-prion protein aggregates. Nat Rev Neurol 2010, 6:702-706.

15. Goedert M, Clavaguera F, Tolnay M: The propagation of prion-like protein inclusions in neurodegenerative diseases. Trends Neurosci 2010, 33:317-325

16. Brundin P, Melki R, Kopito R: Prion-like transmission of protein aggregates in neurodegenerative diseases. Nat Rev Mol Cell Biol 2010, 11:301-307.

17. Frost B, Diamond Ml: Prion-like mechanisms in neurodegenerative diseases. Nat Rev Neurosci 2010, 11:155-159.

18. Sung JY, Kim J, Paik SR, Park JH, Ahn YS, Chung KC: Induction of neuronal cell death by Rab5A-dependent endocytosis of alpha-synuclein. J Biol Chem 2001, 276:27441-27448.

19. Lee SJ: Origins and effects of extracellular alpha-synuclein: implications in Parkinson's disease. J Mol Neurosci 2008, 34:17-22.

20. Volpicelli-Daley LA, Luk KC, Patel TP, Tanik SA, Riddle DM, Stieber A, Meaney DF, Trojanowski JQ, Lee VM: Exogenous alpha-synuclein fibrils induce Lewy body pathology leading to synaptic dysfunction and neuron death. Neuron 2011, 72:57-71.

21. Lee HJ, Suk JE, Patrick C, Bae EJ, Cho JH, Rho S, Hwang D, Masliah E, Lee SJ: Direct transfer of alpha-synuclein from neuron to astroglia causes inflammatory responses in synucleinopathies. J Biol Chem 2010, 285:9262-9272.

22. Hansen C, Angot E, Bergstrom AL, Steiner JA, Pieri L, Paul G, Outeiro TF, Melki R, Kallunki $P$, Fog K, et al: Alpha-Synuclein propagates from mouse brain to grafted dopaminergic neurons and seeds aggregation in cultured human cells. J Clin Invest 2011, 121:715-725.

23. Desplats P, Lee HJ, Bae EJ, Patrick C, Rockenstein E, Crews L, Spencer B, Masliah E, Lee SJ: Inclusion formation and neuronal cell death through neuron-to-neuron transmission of alpha-synuclein. Proc Natl Acad Sci U S A 2009, 106:13010-13015.
24. Kordower JH, Chu Y, Hauser RA, Freeman TB, Olanow CW: Lewy body-like pathology in long-term embryonic nigral transplants in Parkinson's disease. Nat Med 2008, 14:504-506

25. Li JY, Englund E, Holton JL, Soulet D, Hagell P, Lees AJ, Lashley T, Quinn NP, Rehncrona S, Bjorklund A, et al: Lewy bodies in grafted neurons in subjects with Parkinson's disease suggest host-to-graft disease propagation. Nat Med 2008, 14:501-503.

26. Kordower JH, Chu Y, Hauser RA, Olanow CW, Freeman TB: Transplanted dopaminergic neurons develop PD pathologic changes: a second case report. Mov Disord 2008, 23:2303-2306.

27. Wakabayashi K, Yoshimoto M, Tsuji S, Takahashi H: Alpha-synuclein immunoreactivity in glial cytoplasmic inclusions in multiple system atrophy. Neurosci Lett 1998, 249:180-182.

28. Miller DW, Johnson JM, Solano SM, Hollingsworth ZR, Standaert DG, Young AB: Absence of alpha-synuclein mRNA expression in normal and multiple system atrophy oligodendroglia. J Neural Transm 2005, 112:1613-1624.

29. Kikuchi A, Takeda A, Okamura N, Tashiro M, Hasegawa T, Furumoto S, Kobayashi M, Sugeno N, Baba T, Miki Y, et al: In vivo visualization of alphasynuclein deposition by carbon-11-labelled 2-[2-(2dimethylaminothiazol-5-yl)ethenyl]-6-[2-(fluoro)ethoxy]benzoxazole positron emission tomography in multiple system atrophy. Brain 2010, 133:1772-1778.

30. Braak H, Del Tredici K, Rub U, de Vos RA, Jansen Steur EN, Braak E: Staging of brain pathology related to sporadic Parkinson's disease. Neurobiol Aging 2003, 24:197-211.

31. Weinreb PH, Zhen W, Poon AW, Conway KA, Lansbury PT Jr: NACP, a protein implicated in Alzheimer's disease and learning, is natively unfolded. Biochemistry 1996, 35:13709-13715.

32. Miyake E: Establishment of a human oligodendroglial cell line. Acta Neuropathol 1979, 46:51-55.

33. Uezono $Y$, Nakamura E, Ueda $Y$, Shibuya I, Ueta $Y$, Yokoo H, Yanagita T, Toyohira Y, Kobayashi H, Yanagihara N, Wada A: Production of cAMP by adrenomedullin in human oligodendroglial cell line KG1C: comparison with calcitonin gene-related peptide and amylin. Brain Res Mol Brain Res 2001, 97:59-69.

34. Hasegawa T, Baba T, Kobayashi M, Konno M, Sugeno N, Kikuchi A, Itoyama Y, Takeda A: Role of TPPP/p25 on alpha-synuclein-mediated oligodendroglial degeneration and the protective effect of SIRT2 inhibition in a cellular model of multiple system atrophy. Neurochem Int 2010, 57:857-866.

35. Cookson MR: Alpha-Synuclein and neuronal cell death. Mol Neurodegener 2009, 4:9.

36. Kovacs GG, Laszlo L, Kovacs J, Jensen PH, Lindersson E, Botond G, Molnar T, Perczel A, Hudecz F, Mezo G, et al: Natively unfolded tubulin polymerization promoting protein TPPP/p25 is a common marker of alpha-synucleinopathies. Neurobiol Dis 2004, 17:155-162.

37. Orosz F, Kovacs GG, Lehotzky A, Olah J, Vincze O, Ovadi J: TPPP/p25: from unfolded protein to misfolding disease: prediction and experiments. Biol Cell 2004, 96:701-711.

38. Zhang J, Ferguson SS, Barak LS, Menard L, Caron MG: Dynamin and betaarrestin reveal distinct mechanisms for $\mathrm{G}$ protein-coupled receptor internalization. J Biol Chem 1996, 271:18302-18305.

39. Lee HJ, Suk JE, Bae EJ, Lee JH, Paik SR, Lee SJ: Assembly-dependent endocytosis and clearance of extracellular alpha-synuclein. Int J Biochem Cell Biol 2008, 40:1835-1849.

40. Liu J, Zhou Y, Wang Y, Fong H, Murray TM, Zhang J: Identification of proteins involved in microglial endocytosis of alpha-synuclein. J Proteome Res 2007, 6:3614-3627.

41. Otomo M, Takahashi K, Miyoshi H, Osada K, Nakashima H, Yamaguchi N: Some selective serotonin reuptake inhibitors inhibit dynamin I guanosine triphosphatase (GTPase). Biol Pharm Bull 2008, 31:1489-1495.

42. Raimondi A, Ferguson SM, Lou X, Armbruster M, Paradise S, Giovedi S, Messa M, Kono N, Takasaki J, Cappello V, et al: Overlapping role of dynamin isoforms in synaptic vesicle endocytosis. Neuron 2011 70:1100-1114.

43. Takahashi K, Miyoshi H, Otomo M, Osada K, Yamaguchi N, Nakashima H: Suppression of dynamin GTPase activity by sertraline leads to inhibition of dynamin-dependent endocytosis. Biochem Biophys Res Commun 2010, 391:382-387. 
44. Davidson WS, Jonas A, Clayton DF, George JM: Stabilization of alphasynuclein secondary structure upon binding to synthetic membranes. J Biol Chem 1998, 273:9443-9449.

45. Kahle PJ, Neumann M, Ozmen L, Muller V, Jacobsen H, Schindzielorz A Okochi M, Leimer $U$, van Der Putten $H$, Probst A, et al: Subcellular localization of wild-type and Parkinson's disease-associated mutant alpha -synuclein in human and transgenic mouse brain. J Neurosci 2000, 20:6365-6373.

46. Dixon C, Mathias N, Zweig RM, Davis DA, Gross DS: Alpha-synuclein targets the plasma membrane via the secretory pathway and induces toxicity in yeast. Genetics 2005, 170:47-59.

47. Tokuda T, Qureshi MM, Ardah MT, Varghese S, Shehab SA, Kasai T, Ishigami N, Tamaoka A, Nakagawa M, El-Agnaf OM: Detection of elevated levels of alpha-synuclein oligomers in CSF from patients with Parkinson disease. Neurology 2010, 75:1766-1772.

48. El-Agnaf OM, Salem SA, Paleologou KE, Curran MD, Gibson MJ, Court JA, Schlossmacher MG, Allsop D: Detection of oligomeric forms of alphasynuclein protein in human plasma as a potential biomarker for Parkinson's disease. FASEB J 2006, 20:419-425.

49. Alvarez-Erviti L, Rodriguez-Oroz MC, Cooper JM, Caballero C, Ferrer I, Obeso JA, Schapira AH: Chaperone-mediated autophagy markers in Parkinson disease brains. Arch Neurol 2010, 67:1464-1472.

50. Cuervo AM, Stefanis L, Fredenburg R, Lansbury PT, Sulzer D: Impaired degradation of mutant alpha-synuclein by chaperone-mediated autophagy. Science 2004, 305:1292-1295.

51. Vogiatzi T, Xilouri M, Vekrellis $K$, Stefanis L: Wild type a-synuclein is degraded by chaperone mediated autophagy and macroautophagy in neuronal cells. J Biol Chem 2008, 283:23542-23556.

52. Mak SK, McCormack AL, Manning-Bog AB, Cuervo AM, Di Monte DA: Lysosomal degradation of alpha-synuclein in vivo. J Biol Chem 2010, 285:13621-13629.

53. Wenning GK, Stefanova N, Jellinger KA, Poewe W, Schlossmacher MG: Multiple system atrophy: a primary oligodendrogliopathy. Ann Neurol 2008, 64:239-246.

54. Ubhi K, Low P, Masliah E: Multiple system atrophy: a clinical and neuropathological perspective. Trends Neurosci 2011, 34:581-590.

55. Ahmed Z, Asi YT, Sailer A, Lees AJ, Houlden H, Revesz T, Holton JL: Review: The neuropathology, pathophysiology and genetics of multiple system atrophy. Neuropathol Appl Neurobiol 2012, 38:4-24.

56. Nakamura S, Kawamoto Y, Nakano S, Akiguchi I: Expression of the endocytosis regulatory proteins Rab5 and Rabaptin-5 in glial cytoplasmic inclusions from brains with multiple system atrophy. Clin Neuropatho/ 2000, 19:51-56.

57. Kragh CL, Lund LB, Febbraro F, Hansen HD, Gai WP, El-Agnaf O, RichterLandsberg C, Jensen PH: \{alpha\}-Synuclein Aggregation and Ser-129 Phosphorylation-dependent Cell Death in Oligodendroglial Cells. J Biol Chem 2009, 284:10211-10222.

58. Olah J, Vincze O, Virok D, Simon D, Bozso Z, Tokesi N, Horvath I, Hlavanda E, Kovacs J, Magyar A, et al: Interactions of pathological hallmark proteins: tubulin polymerization promoting protein/p25, beta-amyloid, and alphasynuclein. J Biol Chem 2011, 286:34088-34100.

59. Nonaka T, Watanabe ST, Iwatsubo T, Hasegawa M: Seeded aggregation and toxicity of \{alpha\}-synuclein and tau: cellular models of neurodegenerative diseases. J Biol Chem 2010, 285:34885-34898.

60. Angot $E$, Brundin P: Dissecting the potential molecular mechanisms underlying alpha-synuclein cell-to-cell transfer in Parkinson's disease. Parkinsonism Relat Disord 2009, 15(Suppl 3):S143-S147.

61. Bhak G, Choe YJ, Paik SR: Mechanism of amyloidogenesis: nucleationdependent fibrillation versus double-concerted fibrillation. BMB Rep 2009, 42:541-551.

62. Lee HJ, Patel S, Lee SJ: Intravesicular localization and exocytosis of alphasynuclein and its aggregates. J Neurosci 2005, 25:6016-6024.

63. Flower TR, Clark-Dixon C, Metoyer C, Yang H, Shi R, Zhang Z, Witt SN: YGR198w (YPP1) targets A30P alpha-synuclein to the vacuole for degradation. J Cell Biol 2007, 177:1091-1104.

64. Hasegawa T, Konno M, Baba T, Sugeno N, Kikuchi A, Kobayashi M, Miura E, Tanaka N, Tamai K, Furukawa K, et al: The AAA-ATPase VPS4 regulates extracellulr secretion and lysosomal targeting of alpha-synuclein. PLOS One 2011, 6:e29460.

65. Liu J, Zhang JP, Shi M, Quinn T, Bradner J, Beyer R, Chen S, Zhang J: Rab11a and HSP90 regulate recycling of extracellular alpha-synuclein. $J$ Neurosci 2009, 29:1480-1485.
66. Vella $L$, Sharples RA, Lawson VA, Masters CL, Cappai R, Hill AF: Packaging of prions into exosomes is associated with a novel pathway of PrP processing. J Pathol 2007, 211:582-590.

67. Fevrier B, Vilette D, Archer F, Loew D, Faigle W, Vidal M, Laude H, Raposo G: Cells release prions in association with exosomes. Proc Natl Acad Sci U S A 2004, 101:9683-9688.

68. Emmanouilidou E, Melachroinou K, Roumeliotis T, Garbis SD, Ntzouni M, Margaritis LH, Stefanis L, Vekrellis K: Cell-produced alpha-synuclein is secreted in a calcium-dependent manner by exosomes and impacts neuronal survival. J Neurosci 2010, 30:6838-6851.

69. Alvarez-Erviti L, Seow Y, Schapira AH, Gardiner C, Sargent IL, Wood MJ, Cooper JM: Lysosomal dysfunction increases exosome-mediated alphasynuclein release and transmission. Neurobiol Dis 2011, 42:360-367.

70. Lass-Florl C, Dierich MP, Fuchs D, Semenitz E, Jenewein I, Ledochowski M: Antifungal properties of selective serotonin reuptake inhibitors against Aspergillus species in vitro. J Antimicrob Chemother 2001, 48:775-779.

71. Baba T, Takeda A, Kikuchi A, Nishio Y, Hosokai Y, Hirayama K, Hasegawa T, Sugeno N, Suzuki K, Mori E, et al: Association of olfactory dysfunction and brain. Metabolism in Parkinson's disease. Mov Disord 2011, 26:621-628.

72. Baba T, Kikuchi A, Hirayama K, Nishio Y, Hosokai Y, Kanno S, Hasegawa T, Sugeno $N$, Konno M, Suzuki K, et al: Severe olfactory dysfunction is a prodromal symptom of dementia associated with Parkinson's disease: a 3 year longitudinal study. Brain 2012, 135:161-169.

73. Marino S, Sessa E, Di Lorenzo G, Digangi G, Alagna A, Bramanti P, Di Bella P: Sertraline in the treatment of depressive disorders in patients with Parkinson's disease. Neurol Sci 2008, 29:391-395.

74. Ubhi K, Inglis C, Mante M, Patrick C, Adame A, Spencer B, Rockenstein E, May V, Winkler J, Masliah E: Fluoxetine ameliorates behavioral and neuropathological deficits in a transgenic model mouse of alphasynucleinopathy. Exp Neurol 2012, 234:405-416.

75. Paumier KL, Siderowf AD, Auinger P, Oakes D, Madhavan L, Espay AJ, Revilla FJ, Collier TJ: Tricyclic antidepressants delay the need for dopaminergic therapy in early Parkinson's disease. Mov Disord 2012, 27:880-887.

76. Friess E, Kuempfel T, Modell S, Winkelmann J, Holsboer F, Ising M, Trenkwalder C: Paroxetine treatment improves motor symptoms in patients with multiple system atrophy. Parkinsonism Relat Disord 2006, 12:432-437.

77. Ozawa T, Sekiya K, Sekine Y, Shimohata T, Tomita M, Nakayama H, Aizawa N, Takeuchi R, Tokutake T, Katada S, Nishizawa M: Maintaining glottic opening in multiple system atrophy: Efficacy of serotonergic therapy. Mov Disord 2012, 27:919-921.

78. Flabeau O, Meissner WG, Tison F: Multiple system atrophy: current and future approaches to management. Ther Adv Neurol Disord 2010, 3:249-263.

79. Sheerin UM, Charlesworth G, Bras J, Guerreiro R, Bhatia K, Foltynie T, Limousin P, Silveira-Moriyama L, Lees A, Wood N: Screening for VPS35 mutations in Parkinson's disease. Neurobiol Aging 2011.

80. Zimprich A, Benet-Pages A, Struhal W, Graf E, Eck SH, Offman MN Haubenberger D, Spielberger S, Schulte EC, Lichtner P, et al: A Mutation in VPS35, encoding a subunit of the retromer complex, causes late-onset Parkinson disease. Am J Hum Genet 2011, 89:168-175.

81. Vilarino-Guell C, Wider C, Ross OA, Dachsel JC, Kachergus JM, Lincoln SJ, Soto-Ortolaza Al, Cobb SA, Wilhoite GJ, Bacon JA, et al: VPS35 Mutations in Parkinson Disease. Am J Hum Genet 2011, 89:162-167.

82. Da Silva JS, Hasegawa T, Miyagi T, Dotti CG, Abad-Rodriguez J: Asymmetric membrane ganglioside sialidase activity specifies axonal fate. Nat Neurosci 2005, 8:606-615.

83. Hasegawa T, Yamaguchi K, Wada T, Takeda A, Itoyama Y, Miyagi T: Molecular cloning of mouse ganglioside sialidase and its increased expression in Neuro2a cell differentiation. J Biol Chem 2000, 275:8007-8015.

doi:10.1186/1750-1326-7-38

Cite this article as: Konno et al:: Suppression of dynamin GTPase decreases a-synuclein uptake by neuronal and oligodendroglial cells: a potent therapeutic target for synucleinopathy. Molecular

Neurodegeneration 2012 7:38. 